\title{
Nest-climatic factors affect the abundance of biting flies and their effects on nestling condition
}

\author{
Josué Martínez-de la Puente*, Santiago Merino, Elisa Lobato ${ }^{1}$, Juan Rivero-de Aguilar, \\ Sara del Cerro, Rafael Ruiz-de-Castañeda, Juan Moreno
}

Departamento de Ecología Evolutiva, Museo Nacional de Ciencias Naturales (CSIC), J. Gutiérrez Abascal 2, E-28006 Madrid, Spain

\section{eywords:}

Biting midge Culicoides

Black flies

Ficedula hypoleuca

Hosteparasite interactions

Temperature

Vectors

\begin{abstract}
a b s t r a c t
The first step in the establishment of a hostebiting fly relationship is host location. While a number of studies highlight the role of host emitted products as important cues affecting host location by biting flies, the role of host temperature is far from clear. We investigated the role of different nest microclimatic variables affecting the interaction between pied flycatchers and two biting flies: black flies and biting midges. Biting midge abundances increased with temperature inside the nest, supporting the potential importance of nest temperature as a cue used by insects to localize their hosts. The possibility that biting fly infestations were associated to ecological conditions in the vicinity of the nests is also discussed. Furthermore, we found a negative association between nestling weight (including tarsus length as a covariate in the analyses) and the interaction between the abundance of biting midges and the presence/ absence of black flies in nests. The potential negative effect of these ectoparasites on nestling weight (condition index) and potential differences in the bird phenotypic/genetic quality associated with nest site choice and parasite infestations are considered.
\end{abstract}

\section{Introduction}

Location of the hosts by biting flies is a complex and active behavioural task that enhances the probability of contact of haematophagous insects with their hosts (Sutcliffe, 1986). This behaviour could be divided into three phases: (i) appetitive searching, (ii) activation and orientation and (iii) attraction (Lehane, 2005), although the definition of these phases could vary between authors (Kettle, 1995). In addition to vision and smell, other stimuli including heat and humidity become available to the insect in close proximity to their hosts and are also involved in the biting flies' host-seeking behaviour (Gatehouse and Lewis, 1973).

Biting insects may respond to the heat emitted by the host or to the thermal gradient between insects and hosts (Lehane, 2005). There are clear evidences for the role of thermoreceptors of bloodsucking arthropods in responses to thermal stimuli related to the presence of their hosts (Howlett, 1910; Nigam and Ward, 1991; Guerenstein and Lazzari, 2009). However, the importance of host temperature or humidity on host location is far from clear for the

\footnotetext{
* Corresponding author. Present address: Department of Animal Science, Universidad de Las Palmas de Gran Canaria, 35416 Arucas, Spain.

E-mail address: jmartinez@becarios.ulpgc.es (J. Martínez-de la Puente).

1 Present address: Centre d'Ecologie Fonctionelle et Evolutive, CNRS, 1919 Route de Mende, Montpellier, France
}

vast majority of blood-sucking insects, in contrasts to the well-know role of chemical cues (Guerenstein and Lazzari, 2009). In the case of biting flies attacking wild birds the difficulties for sampling insects in avian nests (but see two recent descriptions of easy sampling methods by Tomás et al., 2008a; Votýpka et al., 2009) do the research on these factors even more complicated.

Biting midges (genus Culicoides, Diptera: Ceratopogonidae) and black flies (Diptera: Simuliidae) are two of the main haematophagous insects attacking birds under natural conditions (Kettle, 1995; Malmqvist et al., 2004; Martínez-de la Puente et al., 2009a, 2009b; Votýpka et al., 2009). Among these insects only females feed on animal blood, affecting hosts directly by draining resources and causing physical harassment and indirectly as vectors of multiple pathogens (Bennett, 1961; Valkiūnas, 2005). In spite of the few studies on the effects of biting fly attacks on wild birds, there are clear evidences supporting the role of biting flies increasing mortality in immature birds (Hunter et al., 1997; Smith et al., 1998). These adverse effects on nestlings may be due to the direct impact of insect attacks but also by their effects affecting parental decisions, including nest desertion or reduction of parental provisioning rate (Bukaciński and Bukacińska, 2000).

Here, we investigated the effects of two microclimatic factors, nest temperature and humidity, potentially affecting the relationship between biting flies and avian hosts. To that end, we studied the interaction between pied flycatchers Ficedula hypoleuca and two 
different haematophagous insect groups, biting midges and black flies, after controlling for the potential effect of other variables such as brood size and hatching date (see Martínez-de la Puente et al., 2009b). Also, we investigated the potential negative effect of biting flies on nestling condition after controlling for the confounding effect of rearing conditions (Dawson et al., 2005b; Pérez et al., 2008).

\section{Methods}

\subsection{Host population}

This study was conducted during the spring of 2008 in a population of pied flycatchers $\mathrm{F}$. hypoleuca breeding in nest-boxes in a Pyrenean oak Quercus pyrenaica forest located in Valsaín (Central Spain, $40^{\circ} 53^{0} 74 \mathrm{~N}, 4^{\circ} 01^{0} \mathrm{~W}, 1200$ m.a.s.l.). All nest-boxes were hung from branches at about $4 \mathrm{~m}$ above the ground, thus, avoiding potential height differences in avian exposure to insect attacks (Fallis and Smith, 1964). Periodical visits in the course of the breeding season allowed us to record hatching date and brood size of birds at each nest.

\subsection{Nestling measurements}

At the age of 12 days, nestlings were weighed with a Pesola spring balance to the nearest $0.1 \mathrm{~g}$ and tarsus length was measured with a digital calliper to the nearest $0.01 \mathrm{~mm}$. The average of nestling body mass and tarsus length per brood was calculated. Mass and tarsus length were not significant correlated (Simple regression: $F_{1,44} 1 / 42.55 ; p^{1 / 4} 0.12$ ). Nestling mass was corrected by size by using tarsus length as a covariate in further analyses (see Biard et al., 2005; Suárez et al., 2005; Shapiro et al., 2006 for a similar procedure).

\subsection{Insect collection}

In order to capture biting flies visiting nest-boxes, we put inside and close to the roof of each nest-box a plastic Petri dish (8.5 cm diameter; $56.7 \mathrm{~cm}^{2}$ ) with a thinly spread layer of body geleoil (Johnson's ${ }^{\circledR}$ baby chamomilla, Johnson \& Johnson, Dusseldorf, Germany) when nestlings were 9 days old (see Tomás et al., 2008a for a validation and a thorough description of the method of insect capture). Petri dishes were collected 3 days later. Although daily changes of Petri dishes could provide data on daily variation in biting fly activity, this possibility was discarded to reduce avian disturbance during bird reproduction that could induce nest desertion. According to a previous study, nest-boxes without broods attract almost no biting flies (Tomás et al., 2008a). A stereoscopic microscope (Motic K700; 46.5× magnification) was used to quantify the abundance of black flies and biting midges collected at the bottom of each Petri dish.

\subsection{Rearing conditions in the nests and weather data collection}

A HOBO data logger (Onset Computer Corporation, Pocasset, Massachusetts, USA) with a flexible sensor was placed in each nestbox to record nest temperature $\left({ }^{\circ} \mathrm{C}\right)$ and nest absolute humidity (gm/M3) with a frequency of 2 min during the 3-day period of insect capture. Data loggers were inserted between the nestmaterial and the inner wall of the nest-box, close to the chicks but avoiding any contact with them. The average of nest temperature and nest humidity for the 3 days of sampling was calculated.

The Spanish National Meteorological Institute provided daily maximum and minimum temperature data from the closest meteorological station located in Segovia, approximately $9 \mathrm{~km}$ from the study area. In previous studies, data from this meteorological station have been used to find clear effects of weather on several factors related to avian biology and birdehaematophagous insect interactions carried out in the same area (Sanz et al., 2003; Lobato et al., 2006; Martínez-de la Puente et al., 2009b). Environmental temperature was then estimated by calculating the averages of the maximum and minimum temperatures respectively for each insect sampling period. Furthermore, the temperature gradient between the nest and the environment was estimated in two different ways. In the case of biting midges, the temperature gradient was measured as the difference between temperature in the nest and the minimum environmental temperature because most of the biting midges are considered crepuscular or nocturnal (Lehane, 2005) with a pronounced burst of activity at sunset during spring, summer and autumn (Kettle et al., 1998). However, in the case of black flies, the temperature gradient between the nest and the maximum environmental temperature was calculated because, contrary to biting midges, most adult black flies are essentially diurnal, usually showing a maximum activity in the early morning and afternoon (Lehane, 2005; McCreadie et al., 1985; Grillet et al., 2005). Although there are some reports of nocturnal black fly activity, the level of activity detected in these cases is low (McCreadie et al., 1985) and there are not evidences of black flies attacking avian hosts after dark (Bennett, 1960).

\subsection{Statistical analysis}

Statistical analyses were conducted using Statistica (version 6.0, StatSoft, Inc. 2001). In order to investigate the variables affecting the temperature in avian nests, the Akaike's second-order Information Criterion (AICc) was used for ranking the fit of models to the data (Burnham and Anderson, 1998) including hatching date, brood size and maximum and minimum external temperatures as continuous variables. The same procedure was employed to test for the effect of brood size, hatching date, nest temperature, nest humidity and the temperature gradient (the difference between the nest temperature and the environmental minimum temperature) on the abundance of biting midges. We also used AICc to identify the ranking of models to the presence/absence of black flies in avian nests, including brood size, hatching date, nest temperature, nest humidity and the temperature gradient (the difference between the nest temperature and the environmental maximum temperature) on the abundance of biting midges. We considered that models with a difference in AICc $(\triangle \mathrm{AICc})$ of less than two units (DAIC $<2$ ) were similarly supported by the data. In order to quantify the relative importance of individual variables we calculated variable weights by summing the Akaike weights for each model containing the variable of interest (Johnson and Omland, 2004). All models obtained in the analyses (including those with a difference in AICc higher than two units) were considered to get variable weights.

Finally, to investigate the variables affecting nestling mass, we included in a General Regression Model (GRM, lineal models) the presence/absence of black flies as a factor and hatching date, brood size, nest temperature, nest humidity, tarsus length, biting midge abundance and the interaction between the presence/absence of black flies and biting midge abundance as covariates. This analysis allows us to identify the role of biting midges and black flies as well as their potential joint effect in affecting nestling body mass after control for body size (including tarsus length as a covariate in our analyses). The abundance of biting midges was logarithmically $(\log 10(x p 1))$ transformed to normalize its distribution. Residuals of the model were tested for normality.

In this study, we include 21 control and 25 unmanipulated nests from several experiments carried out in the pied flycatcher population with known nest temperature and humidity. Nests treated as control were sprayed with water 3 times during the incubation period. Unmanipulated nests were visited in the same way as controls but they were not sprayed with any product. As expected, this treatment conducted during the incubation period did not modify significantly 
Table 1

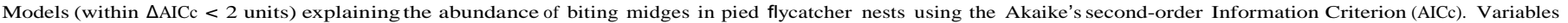
included in each model were marked with " $X$ ". A total of 46 nests were included in this study.

\begin{tabular}{|c|c|c|c|c|c|c|c|c|}
\hline \multirow[t]{2}{*}{ Model } & \multicolumn{5}{|l|}{ Variables } & \multirow[t]{2}{*}{ AICc } & \multirow[t]{2}{*}{$\triangle \mathrm{AICc}$} & \multirow[t]{2}{*}{ Akaike weight } \\
\hline & Brood size & Nest humidity & Nest temperature & Hatching date & Temperature gradient & & & \\
\hline 1 & $\mathrm{X}$ & $\mathrm{X}$ & $\mathrm{X}$ & & & 61.55 & 0 & 0.24 \\
\hline 2 & $\mathrm{X}$ & & $\mathrm{X}$ & & & 62.14 & 0.59 & 0.18 \\
\hline 3 & $\mathrm{x}$ & $\mathrm{X}$ & $\mathrm{x}$ & $\mathrm{X}$ & & 63.36 & 1.81 & 0.10 \\
\hline 4 & $\mathrm{X}$ & $\mathrm{X}$ & $\mathrm{X}$ & & $\mathrm{X}$ & 63.53 & 1.98 & 0.09 \\
\hline
\end{tabular}

nest temperature or humidity during the nestling period (at the age of nestlings of 9 days) when insects were captured (all $p>0.15$ ) so we do not include this variable in further analyses. No experimental manipulations were conducted during the nestling period.

\section{Results}

Overall 1761 biting midges (mean abundance T SD $1 / 438.3$ T 52.4; prevalence $1 / 40.91$; range $1 / 40$ 0227) and 78 black flies (mean

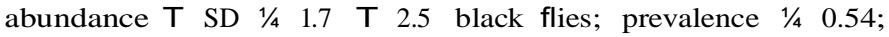
range $1 / 40$ e10) were captured in 46 pied flycatcher nests. Among them, one nest was infested only by black flies, 18 nests were infested only by biting midges and in 24 nests we collected both biting midges and black flies. In three additional nests we did not collect biting flies.

We obtained 15 different models explaining the temperature inside nests, with one model within a difference of less than two units (DAIC < 2) with respect to the best model. The model with the lowest AICc (AICc $1 / 4$ 160.07; w 1/4 0.40) included two variables, environmental minimum temperature and brood size. The other competing model (AICc $1 / 4$ 160.72; w $1 / 4$ 0.29) included environmental minimum temperature, brood size and environmental maximum temperature. Overall, environmental minimum temperature ( $w 1 / 4$ 0.99) and brood size ( $\mathrm{w} 1 / 4$ 0.92) were the variables with higher weights explaining temperature inside nests, followed by environmental maximum temperature ( $\left.\mathrm{w}^{1 / 4} 0.42\right)$ and hatching date ( $\left.\mathrm{w}^{1 / 4} 0.24\right)$.

We found four (DAIC < 2) competing models out of 31 models explaining the abundance of biting midges in pied flycatcher nests

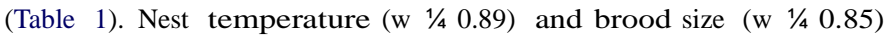
had the higher weights explaining the abundance of biting flies in avian nests followed by nest humidity ( $\left.\begin{array}{c}1 / 4 \\ 0.58\end{array}\right)$, the temperature gradient (the difference between the nest temperature and the environmental minimum temperature) ( $w$ 1/4 0.34) and hatching date $\left(w^{1 / 4} 0.33\right)$. Higher abundances of biting midges were found in

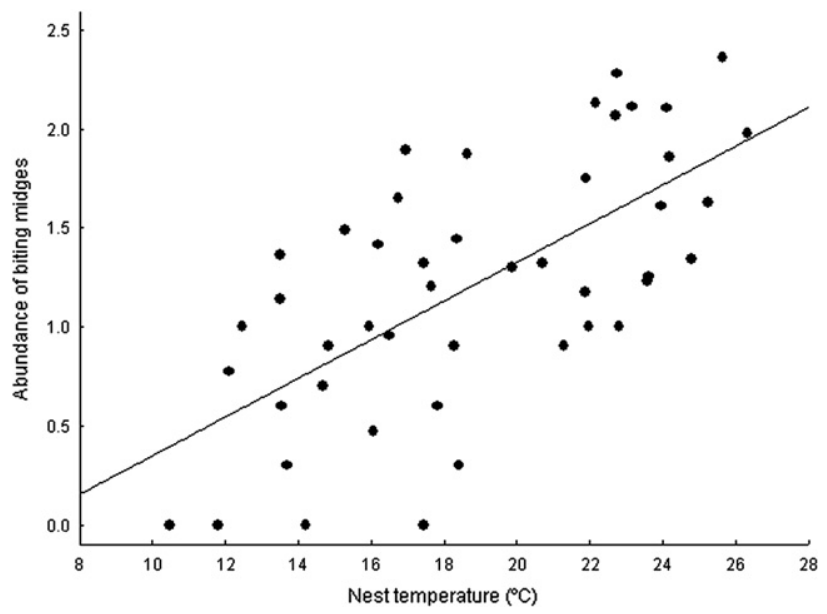

Fig. 1. Relationship between the abundance of Culicoides biting midges (log10 transformed) and the temperature inside pied flycatcher nests. Regression line is shown $\left(r^{2} 1 / 40.44 ; p<0.001 ; y^{1 / 4}-0.63\right.$ p $\left.0.10^{*} x\right)$. warmer nests occupied by larger broods (Fig. 1). In addition, the abundance of biting midges was positively associated with nest humidity (Fig. 2). Furthermore, we obtained four competing models from the total of 31 models to explain the presence of black flies in pied flycatcher nests (Table 2). The variable with the highest weight was brood size ( $\left.\begin{array}{llll}1 / 4 & 0.99\end{array}\right)$ followed by nest humidity

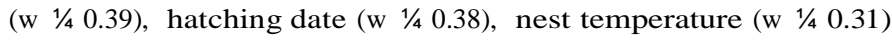
and temperature gradient ( $\left.\begin{array}{llll}w & 1 / 4 & 0.26\end{array}\right)$. Black flies were more frequently found in nests with larger broods.

Average nestling mass was significantly associated with the interaction between the abundance of biting midges and the presence/absence of black flies after control for the effect of different variables (Table 3). Nestling mass decreased as the abundance of biting midges increased, with a more pronounced effect on nestlings suffering also the attack of black flies (Fig. 3). In addition, nestling mass was significant and positively associated with hatching date and tarsus length and negatively with nest temperature (Table 3). We did not find any significant association between nestling mass and the rest of the variables included in the model (Table 3).

\section{Discussion}

Rearing conditions in the nest affect the interaction between avian hosts and nest-dwelling ectoparasites (Eeva et al., 1994; Heeb et al., 2000; Dawson et al., 2005a). However, conclusions from these studies are difficult to apply to the case of biting flies due to the higher mobility and independence of these insects from their hosts as compared to nest-dwelling ectoparasites. According to our correlative results, it is possible that microclimatic conditions were used directly as cues or indirectly as factors contributing to the spread of other host attractants used by biting flies to detect their hosts. Previously, Howlett (1910) reported that females of the mosquitoes Culex fatigans and Stegomyia scutellaris were attracted to heat even if

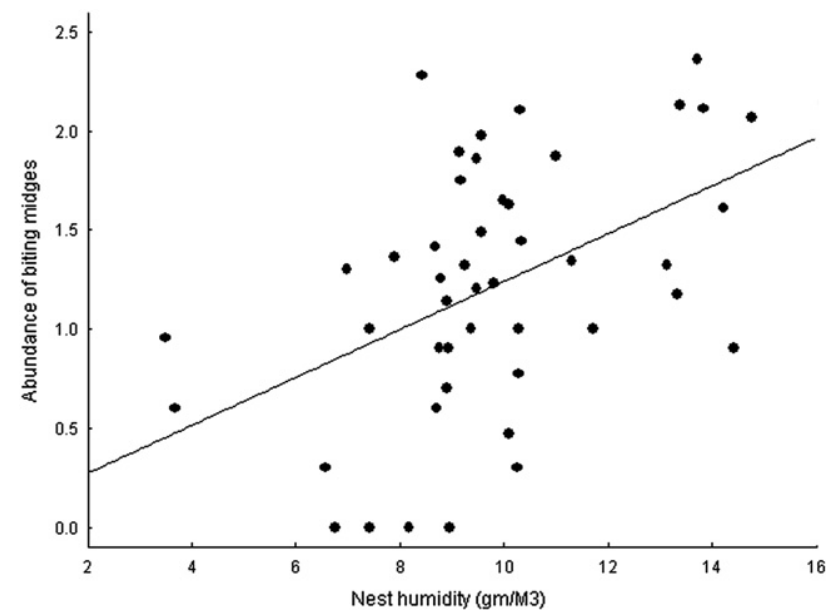

Fig. 2. Relationship between the abundance of Culicoides biting midges (log10 transformed) and humidity inside pied flycatcher nests. Regression line is shown $\left(r^{2} 1 / 40.22\right.$; p $1 / 40.001 ; y 1 / 40.03$ p $0.12 * x)$. 
Table 2

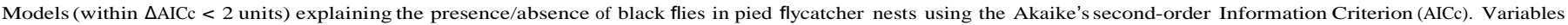
included in each model were marked with " $\mathrm{X}$ ". A total of 46 nests were included in this study.

\begin{tabular}{|c|c|c|c|c|c|c|c|c|}
\hline \multirow[t]{2}{*}{ Model } & \multicolumn{5}{|l|}{ Variables } & \multirow[t]{2}{*}{ AICc } & \multirow[t]{2}{*}{$\triangle \mathrm{AICc}$} & \multirow[t]{2}{*}{ Akaike weight } \\
\hline & Brood size & Nest humidity & Nest temperature & Hatching date & Temperature gradient & & & \\
\hline 1 & $\mathrm{X}$ & & & & & 57.00 & 0 & 0.18 \\
\hline 2 & $\mathrm{X}$ & $\mathrm{X}$ & & & & 57.17 & 0.17 & 0.16 \\
\hline 3 & $\mathrm{X}$ & & & $\mathrm{X}$ & & 57.76 & 0.76 & 0.12 \\
\hline 4 & $\mathrm{X}$ & & $\mathrm{X}$ & $\mathrm{X}$ & & 58.53 & 1.53 & 0.08 \\
\hline
\end{tabular}

this stimulus was not accompanied by other cues. These conclusions were later supported by Marchand (1918) and more recently Kline and Lemire (1995) found also support for the role of heat affecting the host-seeking behaviour of different flies including the biting midge Culicoides furens Poey. According to our results nest humidity may also partially affect the abundance of biting midges in avian nests, although its effect is clearly much lower than the effect of nest temperature. Alternatively, it is possible that the association found between the abundance of biting midges and nests microclimatic conditions could be due to the ecological conditions in the vicinity of the nests and not directly to nest temperature or humidity. However, some important characteristics of nests location such as the distance to water sources do not affect the abundance of biting midges in blue tit nests (Tomás et al., 2008a). It is clear that host related factors, including brood size and hatching date, as well as weather conditions during the insect sampling period are of major importance to influence the abundance of biting flies in avian nests (Martínez-de la Puente et al., 2009a, 2009b). Furthermore, our results suggest that nest temperature did not affect significantly the presence/absence of black flies in avian nests. Contrary to biting midges, black flies have diurnal activity (Lehane, 2005) implying that host-seeking behaviour is activated when differences between environmental and nest temperatures are lower. Diurnal activity imply other advantages for detecting hosts such as the availability of visual cues, given that there are better light conditions to detect colours and higher host mobility during the day than at night (Lehane, 2005). In addition, because during sunny hours there are reduced background levels of atmospheric carbon dioxide (Lehane, 2005), it could be possible that chemicals also play a more important role in host detection by black flies than thermal cues. This conclusion is supported by the study of Fallis and Smith (1964), showing that the ornithophilic simuliid Simulium rugglesi was mainly attracted by an extract from birds plus $\mathrm{CO}_{2}$ or $\mathrm{CO}_{2}$ alone, but much less by heat.

We also found a significant negative association between body mass (including tarsus length as a covariate in the analyses in order to control for the effect of body size) and the interaction between the abundance of biting midges and the presence/absence of black flies. This association could be obviously a reflection of the effects of biting flies on nestlings, directly by draining resources and causing physical harassment but also indirectly as they are vectors of

Table 3

Results of a General Regression Model (lineal model) relating body mass of nestling pied flycatchers Ficedula hypoleuca to brood size, hatching date, nest temperature, nest humidity, tarsus length, the abundance of biting midges, the presence/absence of black flies and the interaction between the abundance of biting midges and the presence/absence of black flies (model: adjusted $r^{2} 1 / 40.41, p<0.001$ ).

\begin{tabular}{lrl}
\hline Variables & $\mathrm{F}_{1,37}$ & $\mathrm{P}$ \\
\hline Brood size & 1.22 & 0.28 \\
Hatching date & 4.75 & 0.04 \\
Nest temperature & 11.42 & 0.002 \\
Nest humidity & 1.03 & 0.32 \\
Tarsus length & 11.88 & 0.001 \\
Biting midge abundance & 0.22 & 0.64 \\
Presence/absence of black flies & 3.12 & 0.09 \\
Biting midge abundance $\times$ presence/absence of black flies & 5.04 & 0.03 \\
\hline
\end{tabular}

several pathogens. Overall, these effects may lead to anaemia and other physiological damages in nestlings, finally affecting their general body condition and survival probability (Hunter et al., 1997; Smith et al., 1998; Tomás et al., 2008b). The fact that, in presence of black flies and abundant biting midges the pathogenic effect on nestling weight was higher than in nests without black flies could be due to several reasons. For example, double infestations may increase the adverse effects suffered by birds because they were inoculated with, and need to respond against, a higher diversity of antigens contained in insect salivary solutions. In fact, insect saliva may affect the haemostatic, inflammatory and immune responses of vertebrate hosts in different ways, thus potentially affecting the expression of the major histocompatibility complex (MHC) (Currie and Hunter, 2008). Moreover, black fly saliva produces an
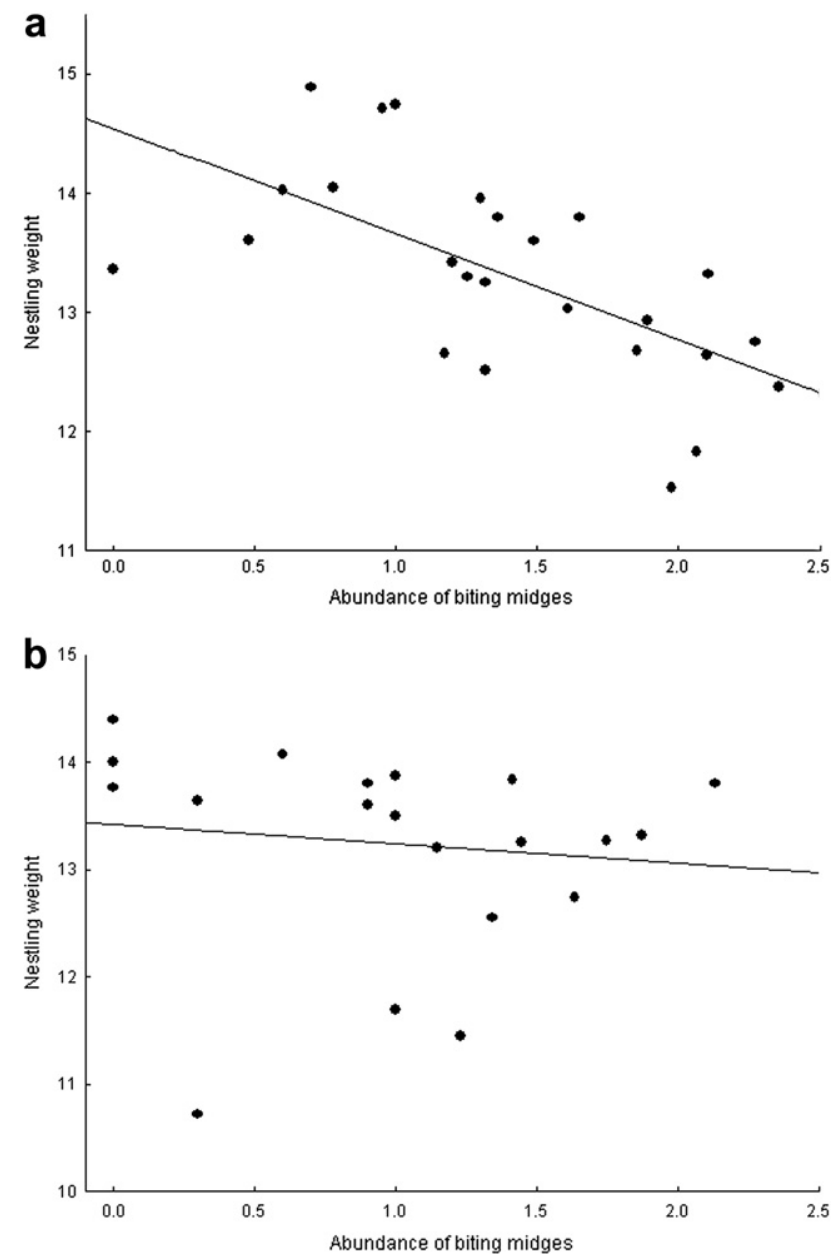

Fig. 3. Relationship between the average of nestling mass and the abundance of Culicoides ( $\log 10$ transformed) in (a) nests with black flies (y $1 / 47.41 \mathrm{e} 0.45^{*} \mathrm{x}$ ) and (B) withlouts blarck01). flies ( $\left.\mathrm{y}^{1 / 4} 2.05 \mathrm{e} 0.08^{*} \mathrm{x}\right)$. Regression lines are shown. (Model: adjusted 
inhibition of lymphocyte mitogenesis (see review by Andrade et al., 2005 and references therein) with potential effects on nestling condition. Additionally, double infestations by biting midges and black flies could increase multiple blood parasite infections because while biting midges are the main vectors of Haemoproteus, other parasites such as Leucocytozoon and Trypanosoma are mainly transmitted by black flies (Bennett, 1961; Valkiūnas, 2005). These blood parasites infect pied flycatcher nestlings in central Spain (Merino and Potti, 1995; Lobato et al., 2005) and multiple infections could be more virulent than single ones (Marzal et al., 2008; del Cerro et al., 2010). Obviously, the effects of the interaction between vectors and parasites on birds merit further studies. Alternatively, the association between fly ectoparasites and nestling mass could be due to other different factors. For example, it could be possible that low quality pairs (i.e. infected birds) rearing nestlings with lower body mass occupied nest-boxes around areas with higher abundances of biting midges and prevalences of black flies. In addition, it could be possible that these low quality birds suffering higher intensities of infection by parasites were more attractive to insect attacks. However, our previous results do not support this possibility, because the abundances of biting midges were negatively associated with the infection status of wild birds (Tomás et al., 2008b; Martínez-de la Puente et al., 2009b).

In conclusion, although correlative, our results support an association between nest temperature and the abundance of parasitic flying insects in avian nests. Furthermore, we found a negative association between nestling condition and biting midge abundance in nests also affected by black flies.

\section{Acknowledgements}

This study was funded by projects CGL2006-14129-C02-01 and CGL2007-61251. Javier Donés (Director of "Montes de Valsaín") gave us permission to work in the study area. S. del Cerro and R. Ruiz-deCastañeda were supported by grants from C.A.M. and JAE-CSIC respectively. During final analyses and writing, support to J.M.P and E.L. was provided by postdoctoral fellowships from the Universidad de Las Palmas de Gran Canaria and Ministerio de Educación y Ciencia respectively. J. Rivero-de Aguilar was not supported by any grant. This study is a contribution to the research developed at "El Ventorrillo" field station. The Agencia Estatal de Meteorología provided weather data. The "Junta de Castilla y León" authorized the ringing and handling of birds (ref. EP/SG/26/2008). This study complies with the current laws of our country. We thank Ó. Gordo for his invaluable help with statistical analyses. Two anonymous referees helped us to improve the manuscript.

\section{References}

Andrade, B.B., Teixeira, C.R., Barral, A., Barral-Netto, M., 2005. Haematophagous arthropod saliva and host defense system: a tale of tear and blood. An. Açad. Bras. Ciênc 77, 665e693 [online].

Bennett, G.F., 1960. On some ornithophilic blood-sucking diptera in Algonquin Park, Ontario, Canada. Can. J. Zool. 38, 377e389.

Bennett, G.F., 1961. On the specificity and transmission of some avian trypanosomes. Can. J. Zool. 39, 17e33.

Biard, C., Surai, P.F., Møller, A.P., 2005. Effects of carotenoid availability during laying on reproduction in the blue tit. Oecologia 144, 32e 44 .

Bukaciński, D., Bukacińska, M., 2000. The impact of mass outbreaks of black flies (Simuliidae) on the parental behaviour and breeding output of colonial common gulls (Larus canus). Ann. Zool. Fennici 37, 43e49.

Burnham, K.P., Anderson, D.R., 1998. Model Selection and Inference: a Practical Information-Theoretic Approach. Springer-Verlag, New York, USA. 353.

Currie, D.C., Hunter, D.B., 2008. Black flies (Diptera: Simuliidae). In: Atkinson, C.T., Thomas, N.J., Hunter, D.B. (Eds.), Parasitic Diseases of Wild Birds. WileyBlackwell, USA, pp. 537e545.

Dawson, R.D., Hillen, K.K., Whitworth, T.L., 2005a. Effects of experimental variation in temperature on larval densities of parasitic Protocalliphora (Diptera: Calliphoridae) in nests of tree swallows (Passeriformes: Hirundinidae). Environ. Entomol. 34, 563e568.
Dawson, R.D., Lawrie, C.C., O'Brien, E.L., 2005b. The importance of microclimate variation in determining size, growth and survival of avian offspring: experimental evidence from a cavity nesting passerine. Oecologia 144, 499e507.

del Cerro, S., Merino, S., Martínez-de la Puente, J., Lobato, E., Ruiz-de-Castañeda, R., Rivero-de-Aguilar, J., Martínez, J., Morales, J., Tomás, G., Moreno, J., 2010. Carotenoid-based plumage colouration is associated with blood parasite richness and stress protein levels in blue tits (Cyanistes caeruleus). Oecologia 162, 825e835.

Eeva, T., Lejikinen, E., Nurmi, J., 1994. Effects of ectoparasites on breeding success of great tits (Parus major) and pied flycatchers (Ficedula hypoleuca) in an air pollution gradient. Can. J. Zool. 72, 624e635.

Fallis, A.M., Smith, S.M., 1964. Ether extracts from birds and $\mathrm{CO}_{2}$ as attractants for some ornithophilic simuliids. Can. J. Zool. 42, $723 e 730$.

Gatehouse, A.G., Lewis, C.T., 1973. Host location behaviour of Stomoxys calcitrans. Entomol. Exp. Appl. 16, 275e290.

Grillet, M.-E., Villamizar, N.J., Cortez, J., Frontado, H.L., Escalona, M., Vivas-Martinez, S., Basanez, M.-G., 2005. Diurnal biting periodicity of parous Simulium (Diptera: Simuliidae) vectors in the onchocerciasis Amazonian focus. Acta Trop. 94, 139e158.

Guerenstein, P.G., Lazzari, C.R., 2009. Host-seeking: how triatomines acquire and make use of information to find blood. Acta Trop. 110, 148 e158.

Heeb, P., Koelliker, M., Richner, H., 2000. Birdeectoparasite interactions, nest humidity, and ectoparasite community structure. Ecology 81, 958e968.

Howlett, F.M., 1910. The influence of temperature upon the biting of mosquitoes. Parasitology 3, 479e484.

Hunter, D.B., Rohner, C., Curie, D.C., 1997. Mortality in fledgling great horned owls from black fly hemathophaga and leucocytozoonosis. J. Wildl. Dis. 33, 486e491.

Johnson, J.B., Omland, K.S., 2004. Model selection in ecology and evolution. Trends Ecol. Evol. 19, 101e108.

Kettle, D.S., Edwards, P.B., Barnes, A., 1998. Factors affecting numbers of Culicoides in truck traps in coastal Queensland. Med. Vet. Entomol. 12, 367e377.

Kettle, D.S., 1995. Medical and Veterinary Entomology, second ed. CAB International, , UK.

Kline, D.L., Lemire, G.F., 1995. Field evaluation of heat as an added attractant to traps baited with carbon dioxide and octenol for Aedes taeniorhynchus. J. Am. Mosq. Control Assoc. 11, 454e456.

Lehane, M., 2005. The Biology of Blood-Sucking in Insects, second ed. Cambridge University Press, Cambridge.

Lobato, E., Moreno, J., Merino, S., Sanz, J.J., Arriero, E., 2005. Haematological variables are good predictors of recruitment in nestling pied flycatchers (Ficedula hypoleuca). Ecoscience 12, 27 e34.

Lobato, E., Moreno, J., Merino, S., Sanz, J.J., Arriero, E., Morales, J., Tomás, G., Martínez-de la Puente, J., 2006. Maternal clutch reduction in the pied flycatcher: an undescribed clutch size adjustment mechanism. J. Avian Biol. 37, 637e641.

Malmqvist, B., Strasevicius, D., Hellgren, O., Adler, P.H., Bensch, S., 2004. Vertebrate host specificity of wild-caught blackflies revealed by mitochondrial DNA in blood. Biol. Lett. 271, S152eS155.

Marchand, W., 1918. First account of a thermotropism in Anopheles punctipennis, with bionomic observations. Psyche 25, 130 e135.

Martínez-de la Puente, J., Merino, S., Lobato, E., Rivero-de Aguilar, J., del Cerro, S., Ruiz-de-Castañeda, R., Moreno, J., 2009a. Does weather affect biting fly abundance in avian nests? J. Avian Biol. 40, 653e657.

Martínez-de la Puente, J., Merino, S., Tomás, G., Moreno, J., Morales, J., Lobato, E., Talavera, S., Sarto i Monteys, V., 2009b. Factors affecting Culicoides species composition and abundance in avian nests. Parasitology 136, 1033e1041.

Marzal, A., Bensch, S., Reviriego, M., Balbontin, J., De Lope, F., 2008. Effects of malaria double infection in birds: one plus one is not two. J. Evol. Biol. 21, 979e987.

McCreadie, J.W., Colbo, M.H., Bennett, G.F., 1985. The seasonal activity of hematophagous diptera attacking cattle in insular Newfoundland. Can. Entomol. 117, 995e1006.

Merino, S., Potti, J., 1995. High prevalence of hematozoa in nestlings of a passerine species, the Pied Flycatcher, Ficedula hypoleuca. Auk 112, 1041 e1043.

Nigam, Y., Ward, R.D., 1991. The effect of male sandfly pheromone and host factors as attractants for female Lutzomyia longipalpis (Diptera: Psychodidae). Physiol. Entomol. 16, 305e312.

Pérez, J.H., Ardia, D.R., Chad, E.K., Clotfelter, E.D., 2008. Experimental heating reveals nest temperature affects nestling condition in tree swallows (Tachycineta bicolor). Biol. Lett. 4, 468e471.

Sanz, J.J., Potti, J., Moreno, J., Merino, S., Frias, O., 2003. Climate change and fitness components of a migratory bird breeding in the Mediterranean region. Glob. Change Biol. 9, 461e472.

Shapiro, B.J., Garant, D., Wilkin, T.A., Sheldon, B.C., 2006. An experimental test of the causes of small-scale phenotypic differentiation in a population of great tits. J. Evol. Biol. 19, 176e183.

Smith, R.N., Cain, S.L., Anderson, S.H., Dunk, J.R., Williams, E.S., 1998. Blackflyinduced mortality of nestling red-tailed hawks. The Auk 115, 368e375.

Suarez, F., Traba, J., Herranz, J., 2005. Body mass changes in female tawny pipits Anthus campestris during the nesting stage. J. Ornithol 146, 372e376. Sutcliffe,

J.F., 1986. Black fly host location: a review. Can. J. Zool. 64, 1041e1053. Tomás, G.,

Merino, S., Martínez-de la Puente, J., Moreno, J., Morales, J., Lobato, E., 2008a. A simple trapping method to estimate abundances of blood-sucking flying insects in avian nests. Anim. Behav. 75, 723e729.

Tomás, G., Merino, S., Martínez-de la Puente, J., Moreno, J., Morales, J., Lobato, E., 2008b. Determinants of abundance and effects of blood-sucking flying insects in the nest of a hole-nesting bird. Oecologia 156, 305e312.

Valkiūnas, G., 2005. Avian Malaria Parasites and Other Haemosporidia. CRC Press, Boca Raton.

Votýpka, J., Synek, P., Svobodová, M., 2009. Endophagy of biting midges attacking cavity-nesting birds. Med. Vet. Entomol. 23, 277e280. 